\title{
Necessity is the mother of invention: William Stewart Halsted's addiction and its influence on the development of residency training in North America
}

\author{
James R. Wright Jr., MD, PhD \\ Norman S. Schachar, MD
}

Accepted May 21, 2019

\section{Correspondence to:}

J.R. Wright Jr

Departments of Pathology \& Laboratory

Medicine and Paediatrics

University of Calgary

Alberta Children's Hospital

28 Oki Drive NW

Calgary AB T3B 6A8

jim.wright@cls.ab.ca

DOI: $10.1503 /$ cjs.003319

\section{SUMmARY}

William Stewart Halsted developed a novel residency training program at Johns Hopkins Hospital that, with some modifications, became the model for surgical and medical residency training in North America. While performing anesthesia research early in his career, Halsted became addicted to cocaine and morphine. This paper dissects how his innovative multi-tier residency program helped him hide his addiction while simultaneously providing outstanding patient care and academic training.

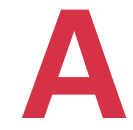

$\mathrm{t}$ a time when surgical educators are considering changes to the structure and content of postgraduate surgical residency education, ${ }^{1-3}$ it is interesting and important to reflect on the factors and influences that formed the classical surgical residency program prototype. The structure of modern residency programs in North America originated at Johns Hopkins Hospital during the last decade of the 19th century. This article examines the first modern surgical residency program that developed under the aegis and influence of William Stewart Halsted (1852-1922).

Halsted was a surgical innovator who greatly shaped surgical practice in the 20th century. ${ }^{4-7}$ While he is generally remembered for perfecting and disseminating the radical mastectomy, ${ }^{8}$ within his profession his accomplishments were legion. Perhaps his most important contribution to the field of surgery was educational. Halsted developed a novel residency training program while at Johns Hopkins Hospital that, with some modifications, became the model for surgical and medical residency training in North America. ${ }^{9}$ However, it should be noted that Halsted's residency was not the first in America; in fact, it was not even the first at Johns Hopkins Hospital. Ludmerer, in his book on the history of residency training, considers William Osler (1849-1919) to have started the first modern North American residency. Halsted's surgical residency was second, and this was soon followed by residencies in gynecology and pathology. Johns Hopkins Hospital was clearly the source of the modern residency training concept in North America. ${ }^{10}$

Halsted's surgical career is usually divided into his early years in New York and his later years in Baltimore. As a young surgeon in New York, Halsted was a highly skilled, bold, fast and daring surgeon who was charismatic and sociable and excelled at teaching medical students. In Baltimore, he was a slow and meticulous surgeon who was a recluse and who avoided teaching medical students when possible. Between these 2 periods, Halsted and some colleagues accidentally became addicted to cocaine, when in late 1884 they, being aware of a new report that cocaine could be used as local anesthesia, experimented upon themselves. Halsted's career in New York rapidly deteriorated, and he was in and out of addiction treatment facilities. Halsted soon became addicted to morphine, which he used to treat his cocaine addiction. 
Halsted moved to Baltimore and began surgical research on dogs in William Welch's laboratory at Hopkins. In the wake of some brilliant animal research on intestinal anastomoses, Halsted was appointed head of the outpatient department, acting surgeon to Johns Hopkins Hospital, and associate professor of surgery. Continued success resulted in Osler and William Welch (1850-1934) recommending Halsted to be surgeon-in-chief in 1890 and Hopkins' first professor of surgery in 1892.6,7 Though everyone believed that Halsted's addiction was cured at the time of these appointments, it later became clear that wasn't the case and that he was able to hide his addiction under a veil of eccentricity and a pyramid of residents.

This paper explores the possible role of Halsted's attempts to hide his addiction in the development and evolution of his surgical residency training program at Johns Hopkins Hospital. We also address the dissemination of the Halsted School by his trainees, and its subsequent evolution into the standard model for residency in North America. Our essay relies extensively upon "nuanced reinterpretation" of known facts and published quotes from Halsted, his former trainees, and other surgical scholars who have written about Halsted.

\section{The Halsted School}

Halsted's dramatic change in surgical style from his New York to his Baltimore days was likely a consequence of both his addiction and his increasing appreciation of the importance of conservative, physiologic surgery gained through his animal studies. Ironically, his physical and mental inability to continue to be a bold and brilliant surgeon helped him realize that a more contemplative, physiologic style, in which conserving tissue and blood was more important than speed, achieved better results. This trend was in its infancy elsewhere, but fully developed within the Halsted School at Hopkins, ${ }^{11,12}$ where Halsted's frailty further reinforced his transition to this new operative style. Daniel B. Nunn, while Historian of The Halsted Society, noted that "Halsted is properly credited as the 'father of a school of safety in surgery,' a school in which brilliance and speed of execution were subordinated to accurate, safe, and thorough performance ..."13

However, knowing what we know now, it was possibly self-serving to be at the forefront of teaching this new style of surgery because, as his own reflexes, speed, and precision deteriorated, he could cover this by delegating work to his resident while stressing accuracy, safety and thorough performance. It also allowed him to spend less time at the operating table and more time in private contemplation. When Halsted operated in front of visiting surgeons, he was so slow that it was painful for the audience to watch. William Mayo (1861-1931), while restlessly watching Halsted perform his signature radical

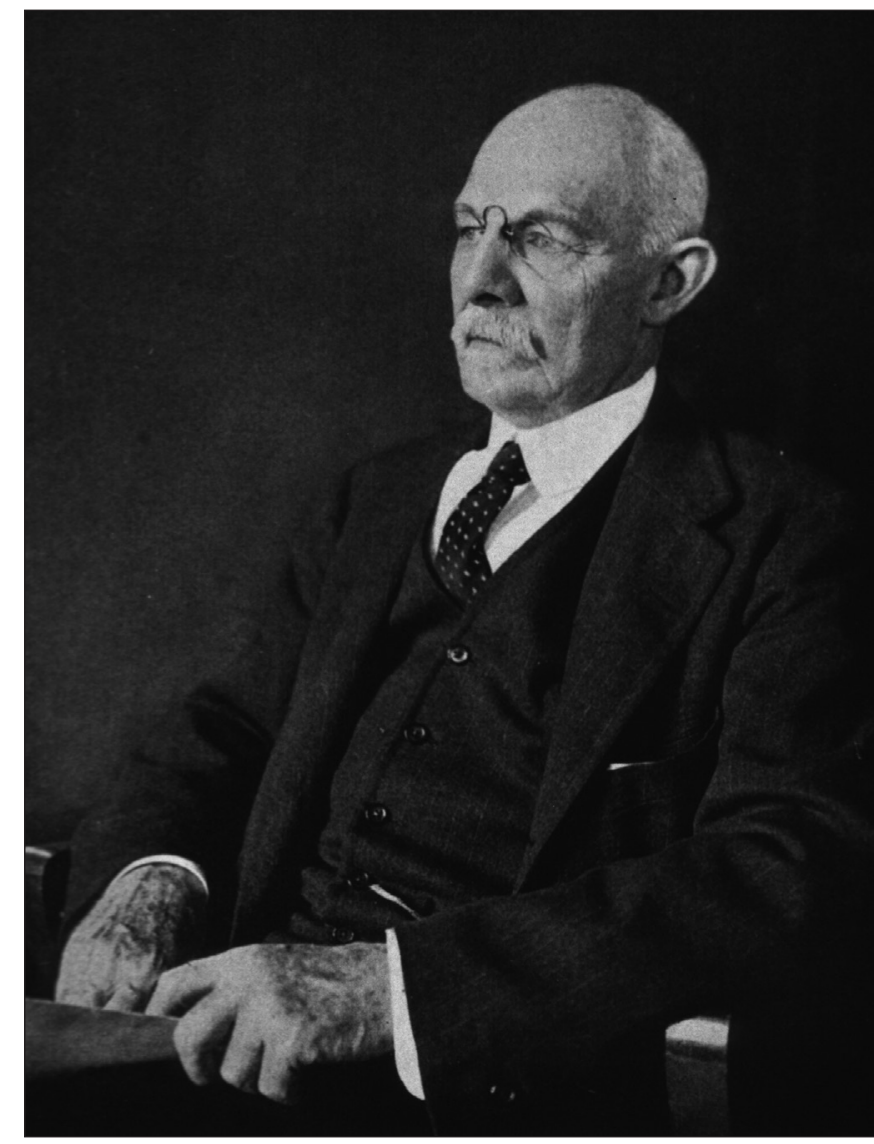

Fig. 1. William Steward Halsted shortly before his death in 1922. Photograph by John H. Stockdale, in the public domain. Source: U.S. National Library of Medicine. Available: https://collections.nlm.nih.gov/catalog/nlm:nlmuid-101417923-img.

mastectomy, once quipped "I have never seen a wound operated at the top while the bottom was already healed." "

The Halsted School also embraced the geographic full time (GFT) payment model that was being implemented at Hopkins, even though most clinical faculty preferred to remain fee-for-service. ${ }^{8}$ Former resident Samuel J. Crowe provides Halsted's thoughts on remuneration:

Monetary rewards were necessary or advisable only to the extent of allowing the doctor to care for his family, to travel in order to acquire new ideas, and to have the leisure and peace of mind to think and read and try to add something during his lifetime of lasting value to medicine. This was in 1905 . No doubt it was for these reasons that [Halsted] enthusiastically welcomed the Full Time Plan when it came along in 1913.14

A complete historical analysis of the implementation of the GFT system at Hopkins is provided elsewhere. ${ }^{15}$ Research, which was facilitated by the GFT model, was another important element of the Halsted School.

\section{Structure OF THE HALSTED RESIDENCY}

Halsted's residency program provided a formal and structured form of education for surgical trainees, 
replacing the apprenticeship training model that had existed before it. Halsted based his training model on elements of surgical training he had observed in Germany. One fundamental element to Halsted's model was that there were tiers, including multiple entry- and midlevel positions, but only 1 senior position. Junior trainees learned hands-on patient management and operative skills under the supervision of a more senior resident rather than the professor. As residents became more experienced, they were given increased responsibility and independence. Furthermore, residents were expected to develop an understanding of the scientific basis of surgical disease and to perform research. The duration of training was indefinite, and advancement to the next level was uncertain, as there was a pyramidal structure with intense competition for advancement to the next level. Many trainees left after completing only an internship or an assistant resident role. For those making it to the top of Halsted's training program, the resident position, it was exceptional academic and clinical training. The resident not only ran the clinical services, but also oversaw the entire training program, functioning like a current day residency program director.

It should be noted, however, that this structure was self-serving for a surgeon hiding his addiction, as the clinical service did not depend on Halsted always being at his best in order to achieve the excellent surgical results he demanded. The pyramidal nature of the program also minimized Halsted's need for day-to-day interaction with trainees, medical and surgical colleagues and patients, thus allowing him to hide his impairment. The energetic cadre of surgical trainees provided Halsted a motivated workforce that was anxious to please him and that he did not need to pay. Such a model could not have worked in most North American training hospitals, as it would have been far too costly to have so many house staff. As noted by other authors, ${ }^{16,17}$ this was likely only possible in one place - the Johns Hopkins Hospital — which, because of its endowments and eventually its GFT payment model, had deep pockets.

Fortunately, a rigid pyramidal structure proved not to be critical for its implementation elsewhere. George J. Heuer (1882-1950) proved this in Cincinnati.

\section{George J. Heuer and the disciples}

Heuer was the 13 th resident trained by Halsted. He served in this role from 1911 to 1914 . He was then appointed associate professor of surgery and associate surgeon at Johns Hopkins. After serving in the First World War, Heuer returned to Hopkins only to find that Halsted had appointed Walter Dandy (1886-1946), a resident who had trained after him, to the position of chief of the neurosurgical service. Heuer had been interested in this position since Harvey Cushing (1869-1939), another former Halsted resident, had been recruited to the Peter Bent Brigham Hospital in Boston in 1912. Heuer was recruited to Cincinnati as the first recipient of the Christian R. Holmes Chair in Surgery in 1922, where he established a surgical residency. ${ }^{16,18,19}$ At this time, it should be noted that the only other Halstedian program was the one in Boston run by Harvey Cushing. Heuer brought several prominent Hopkins-trained surgeons with him, including Mont Reid (1889-1943) and Burr Noland (Nick) Carter (1894-1980). Heuer met immediate resistance from the local surgeons, who stated that "the conversion of a ward of the general patients into private rooms for Professor Heuer was an immorality to the tax payer" and tried to turn it into an issue about "dividing fees," which was against the policies of the American College of Surgeons. ${ }^{16}$ This problem was eventually resolved by building a new private pavilion named Holmes Hospital.

According to David W. MacFadden, Heuer's "adaption of the Halstedian residency training program has been described as the basis on which all good training programs exist today." 16 This is certainly true, because it would not have been possible to duplicate the Hopkins model elsewhere as there would have been insufficient money to pay for multiple tiers of house staff at the base of the pyramid below the resident. When Heuer was recruited to New York Hospital and Cornell in 1932, he encountered difficulties similar to those at Cincinnati. ${ }^{19}$ A recent paper describes how the Halstedian surgical residency model further evolved "from an uncommon, idiosyncratic experience for elite practitioners to a standardized mandatory education for all American surgeons" between the 1930s and the $1950 \mathrm{~s}^{20}$

Another Hopkins-trained assistant surgeon who had been recruited by Heuer and who completed his residency in Cincinnati, Nick Carter, published a remarkable survey in 1952 on the centenary of Halsted's birth. Halsted had directed his surgical residency for 33 years and appointed 17 residents and 55 assistant residents. Carter summarizes how many of these trainees became top academic surgeons and trained the next generation of academic surgeons. ${ }^{21}$ These became Halsted's extensive cadre of surgical disciples. In a second study, Carter also found a high level of academic success in Cincinnati after its surgery residency program had been in operation there for 25 years. ${ }^{22}$ Approximately two-thirds of its trainees held faculty positions, thus generating more disciples. Likely, the offspring of Halsted's many disciples and their disciples have influenced almost all residency training programs in North America.

\section{Consequences of Halsted's addiction}

The most obvious effect of Halsted's addiction on his career was that "he became a slow, painstaking surgeon 
who devoted his life to scientific investigation, organization of a surgical residency, development of improved operative techniques, and intense study of surgical problems; in essence, he concentrated on contemplation and reflection rather than the performance of many operations." 23

Howard Markel notes negative consequences:

...in addition to Halsted's erratic behaviour in the operating room, circumstantial evidence - ranging from his frequent absences from the hospital when his whereabouts were unknown to his avoidance of close colleagues when he was walking the wards (perhaps because he was under the influence and did not wish to be scrutinized by those who might recognize this), his going home daily at 4:30 p.m. and locking himself in his study for 90 minutes before dinner, his curious habit of sending his soiled linen to an exclusive laundry in Paris (which may have sent back more than clean shirts), and, most troubling, his easy access to morphine and to the cocaine that was used in the operating room... - suggests that he continued to abuse morphine and, I suspect, cocaine until the end of his life. ${ }^{24}$

In fact, Halsted had multiple unexplained absences, including a 5-6 month absence in 1895-6, when he ignored the Board of Trustees' repeated attempts to get him to return and was referred to the medical board for discipline. ${ }^{23}$ Conveniently, Joseph Colt Bloodgood (18671935), Halsted's third resident (since 1893), ${ }^{8}$ simply stayed on with Harvey Cushing as an assistant resident. This was essentially an all-star team covering his absence. Shortly after this, Bloodgood was promoted to associate in surgery, serving as Halsted's first assistant, and Harvey Cushing was promoted to resident. ${ }^{8}$ As Paul Friedman correctly notes: "If Halsted were practising today, he would probably be summarily fired from his position and lose his license to practise medicine." 25 In fact, it is unlikely that this behaviour would have been accepted even then, had it been well known. Those who might have suspected did not pursue their suspicions. Even Osler and Welch did not turn him in once they knew; undoubtedly they could justify this, as addiction was poorly understood and Halsted was running a safe, world-class surgical service. Certainly, considering the power differential, his trainees who observed bizarre behaviours were not in a position to turn him in; furthermore, most were beholden to him. For additional details on Halsted's addiction, see Appendix 1 at canjsurg.ca/003319-a1.

According to Deryl Hart, a former Halsted resident who went on to start the Duke University surgical residency, "The two events that seem to have influenced Dr. Halsted more than any others in the development of his residency system were his European experiences, particularly the first two years of study, and his accidental addiction to cocaine." ${ }^{26}$ While it appears that Hart's comment supports our premise, he did not choose to expand on the latter part of this statement.

\section{The German system and its influence on Halsted}

Europe, particularly Germany, was the Mecca for additional medical and surgical training in the latter half of the 19th century, and new medical graduates with the means to study abroad flocked there. After graduating from medical school, Halsted went to Europe from 1878 to 1880 to study both basic sciences, primarily anatomy, and surgery. As the son of a well-to-do businessman in New York, he had the means to study with at least 19 different European medical/surgical scholars. As noted by Rutkow, this allowed him to acquire "an intellectual and cultural eclecticism so important to his work of later life." ${ }^{27}$ Halsted's ideas about surgical education and training were profoundly influenced by this trip. Rutkow concludes that "Halsted drew from many sources, but the most important was the collective educational experience of his first visit to Europe in 1878-1880."27

Halsted clearly modelled his residency training program at Hopkins on the German system. In particular, he admired its integration of basic sciences and practical clinical training, the presence of full-time faculty, and the competitiveness for advancement, which allowed only the very best to rise to the top. According to Rutkow,

His surgical residency system, though, was not an exact duplicate of the German approach, but instead a close compromise. He insisted on a more clearly defined pattern of organization and division of duties. There was a larger volume of operative material at the disposal of the residents, a more intimate contact with practical clinical problems, less preoccupation with pure basic sciences and a concentration of responsibility and authority in the resident rather than the teacher. ${ }^{27}$

All of these differences might be predictable for a high-functioning addict striving to maintain a high degree of order around him. Others have noted that one of the ways he functioned while addicted was by maintaining a highly ordered lifestyle, both at work and at home. ${ }^{6,24}$ Leaving much of the operative work and resolution of clinical problems to his highly skilled and motivated cadre of residents and giving his residents increased responsibility clearly promoted resident education, but these tendencies were also self-serving as delegation of these responsibilities allowed Halsted to maintain a lower day-to-day profile and spend much of his time in contemplation. Even selection and promotion of residents, which was critical to the success of his whole operation, was sometimes delegated to the senior resident, who spent more time with Halsted's workforce than Halsted did and, thus, was in a better position to make these important decisions. 


\section{How did Halsted's Residency PROGRgam compare WITH OTHERS AT HOPKINS?}

A direct comparison with the 3 other contemporary Hopkins residency programs helps build a compelling case that a need to hide his addiction played a role in the design of Halsted's surgical residency program. As noted earlier, Osler developed the first modern residency training program; shortly after this, Halsted, Howard A. Kelly (1958-1943) and Welch developed programs in surgery, gynecology and pathology, respectively. ${ }^{10}$ All early Hopkins' residencies are thought to be at least loosely based on German models; in fact, the overall educational program at Hopkins Medical School was as well. While all clinical disciplines had internships, none of these other 3 founding Hopkins professors appear to have developed a rigidly pyramidal residency model and, therefore, the training they offered was more personal and hands-on. Osler trained 5 residents during his 15 years at Hopkins; their tenures ranged from 15 months to 7 years. While there were likely some assistant residents, little is known about them. The lengthy tenure of Osler's 5 residents, who as "house officers" lived in the hospital, met Osler's lifestyle needs and allowed him to travel. Osler's residents were frequently guests at his house, and several of them had keys to his house so that they could access books in his library when he was away. ${ }^{28}$ This was in stark contrast with Halsted's distant relationship with his residents and his secretive lifestyle. While Kelly is considered to be the father of modern gynecology residency training, ${ }^{29}$ little has been written about its structure; however, it was clearly not a rigid pyramid, since it is known that Thomas S. Cullen (1868-1953) began his residency in 1896 and was hired into a junior staff position in $1897 .{ }^{30}$ Welch's pathology residency was not a pyramid. ${ }^{31}$ While each of these programs was likely designed in part to meet the needs of each mentor, none had the high level of redundancy of Halsted's program or were designed in such a way as to protect its professor from day-to-day scrutiny.

Notably, the 2 other clinicians capable of earning clinical incomes, Osler and Kelly, were strongly opposed to the GFT remuneration system. In fact, Kelly resigned from Hopkins over this issue, moving his practice to Baltimore hospitals allowing fee-forservice private practice. ${ }^{29}$ Although Osler had moved to Oxford almost 10 years earlier, he vocally opposed the implementation of the GFT system at Hopkins when it was announced. ${ }^{32,33}$ Halsted, on the other hand, embraced it, as he was independently wealthy and it subsidized his residency. Both Osler and Kelly had lucrative private practices that they managed without involving trainees.

\section{Conclusion}

The surgical residency model originated with Halsted in the 19th century; it was partially based on a German model, but many aspects of Halsted's program were carefully designed to help him hide his addiction and simultaneously optimize care for his patients. A critical element was providing Halsted with ample time for contemplation, which was possible only because of the extreme delegation of clinical and educational work to his trainees, which as noted above, was a unique element not seen in the other contemporary Hopkins residency programs.

Halsted's model was modified by Heuer to work outside of the Hopkins environment, and this model essentially became the North American standard. While resident advancement in the current North American system is predictable and "square-shaped," some pyramidal programs persisted for the first three-quarters of the 20th century. Finally, it should be noted that the brilliance of Halsted's residency concept was initially affirmed by his former residents, when they became the surgical leadership of the first half of the 20th century. ${ }^{17}$ Furthermore, by agreeing that his greatest accomplishment was his residency program, his former residents, who had each invested 12-14 years in training (much of it working for free), ${ }^{34}$ simultaneously conferred upon themselves the status being one of his greatest accomplishments. While in some ways this is self-serving, in many ways, they really were. ${ }^{5}$

At a time when surgical residencies are undergoing radical and dramatic changes, we should reflect on the history of surgical residency programs and the influencing factors that shaped these programs. Our analysis identifies and highlights Halsted's addiction as an important factor. While we are not condemning Halsted, we are suggesting that if one carefully analyzes and critiques the motivation for the structure of the Halsted surgical residency, his addiction was a major influencing factor.

Acknowledgements: The authors thank Charlotte Monroe, Thomas Kryton, BFA, the University of Calgary Interlibrary Loan Service, and Kristin Rodgers, MLIS, Collections Curator, The Ohio State University Medical Heritage Center, Columbus, OH.

Affiliations: From the Departments of Pathology \& Laboratory Medicine, Paediatrics, and Surgery, University of Calgary Cumming School of Medicine, Calgary, Alta. (Wright, Schachar).

Funding: J.R. Wright Jr. was scholar-in-residence at The Ohio State University Medical Heritage Center, Columbus, $\mathrm{OH}$.

Competing interests: None declared.

Contributors: Both authors contributed substantially to the conception, writing and revision of this article and approved the final version for publication. 


\section{References}

1. Greenberg JA, Minter RM. Entrustable professional activities: the future of competency-base education in surgery may already be here. Ann Surg 2019;269:407-8.

2. Ten Cate O. Competency-based postgraduate medical education: past, present and future. GMS F Med Educ 2017;34:Doc69.

3. Jones MD Jr, Lockspeiser TM. Proceed with caution: implementing competency-based graduate medical education. 7 Grad Med Educ 2018;10:276-8

4. MacCallum WG. William Stewart Halsted, Surgeon. Baltimore, MD: The Johns Hopkins Press, 1930.

5. Crowe SJ. Halsted of Johns Hopkins. The Man and his Men. Springfield, Illinois: Charles C. Thomas, Bannerstone House, 1957.

6. Osborne MP. William Stewart Halsted: his life and contributions to surgery. Lancet Oncol 2007;8:256-65.

7. Imber G. Genius on the Edge. The Bizarre Double Life of Dr. William Stewart Halsted. New York, NY: Kaplan Publishing, 2011.

8. Wright JR Jr. The radicalization of breast cancer surgery: Joseph Colt Bloodgood's role in William Stewart Halsted's legacy. Bull Hist Med 2018;92:141-71.

9. Harvey AM. The influence of William Stewart Halsted's concepts of surgical training. Fobns Hopkins Med 7 1981;148:215-36.

10. Ludmerer KM. Let Me Heal. The Opportunity to Preserve Excellence in American Medicine. New York, NY: Oxford University Press; 2015.

11. Schlich T. The days of brilliancy are past': skills, styles and the changing rules of surgical performance, ca. 1820-1920. 7 Med Hist 2015;59:379-403.

12. Brieger GH. From conservative to radical surgery in late nineteenthcentury America. In: Lawrence C, ed. Medical Theory, Surgical Practice: Studies in the History of Surgery. London: Routledge; 1992:216-31.

13. Nunn DB. William Stewart Halsted - a profile of courage, dedication, and scientific search for truth. F Vasc Surg 1989;10:221-9.

14. Crowe S. Recollections of William Steward Halsted; a great surgeon. Bull fohns Hopkins Hosp 1949;84:15-23.

15. Fye WB. The Origin of the full-time faculty system: implications for clinical research. FAMA 1991;265:1555-62.

16. McFadden DW. George J. Heuer: a commemorative review. South Med f 1990;83:821-6.
17. Rutkow IM. Moments in surgical history: William Stewart Halsted. Arch Surg 2000;135:1478.

18. Andres WD. George J. Heuer's contributions and his place in American surgery. Surgery 1948;23:321-5.

19. Griswold ML. George J. Heuer, M.D. - a critical analysis of the role that he played in introducing the residency system of training. Surgery 1975;78:1-25.

20. Barr J. The education of American surgeons and the rise of surgical residencies, 1930-1960. 7 Hist Med Allied Sci 2018;73:274-302.

21. Carter BN. The fruition of Halsted's concept of surgical training. Surgery 1952;32:518-27.

22. Carter BN. Twenty-five years of a graduate school of surgery founded by George J. Heuer. Surgery 1948;23:326-36.

23. Nunn DB. William Stewart Halsted: transitional years. Surgery 1997;121:343-51.

24. Markel H. The accidental addict. N Engl F Med 2005;352:966-8.

25. Friedmann P. The arduousness of excellence. Arch Surg 1998;133:354-60.

26. Hart D. Historical aspects of surgical residency programs. NC Med $\mathcal{F}$ 1964;25:43-8.

27. Rutkow IM. William Stewart Halsted and the Germanic influence on education and training programs in surgery. Surg Gynecol Obstet 1978;147:602-6.

28. Bryan CS. Residency training in medicine, William Osler's influence on. In: Bryan CS, ed. Sir William Osler: an encyclopedia. Novato (CA): Jeremy Norman; 2020.

29. Davis AW. Dr. Kelly of Hopkins: Surgeon, Scientist, Christian. Baltimore: Johns Hopkins Press, 1959.

30. Robinson J. Tom Cullen of Baltimore. Toronto: Oxford University Press, 1949.

31. Caturegli P, McCarthy EF, Jackson JB, et al. The pathology residency program of the Johns Hopkins University School of Medicine: a model of its kind. Arch Pathol Lab Med 2015; 139:400-6.

32. Harrell GT. Osler's practice. Bull Hist Med 1973;47:545-68.

33. Harrell GT. Osler's professorships and his families. Perspect Biol Med 1985;29:76-87.

34. Halsted WS. The training of the surgeon. Bull fohns Hopkins Hosp $1904 ; 15: 267-75$ 